\title{
Appreciating a World Heritage Site using Multisensory Elements: A Case Study in Kinabalu Park, Sabah, Malaysia
}

\author{
R. Zainol ${ }^{1,2}$
}

${ }^{1}$ Department of Urban and Regional Planning, Faculty of Built Environment, University of Malaya, 50603 Kuala Lumpur, Malaysia

${ }^{2}$ Associate Member of UMSerge, University of Malaya, 50603 Kuala Lumpur, Malaysia

\begin{abstract}
Nature based tourism products offer valuable experience to visitors which can only be appreciated or stimulated using sensory elements. Visual, sound, taste, smell, touch and mobility are sensory elements that are able to enhance visitors' experience in any particular destination. However, some destinations might not provide all the elements. Therefore this study's objective is to assess the role of multisensory experience in appreciating the natural heritage of Kinabalu Park. Participant observation is used to carry out the assessment. Findings show visitors are able to appreciate Kinabalu Park using five main sensory elements namely visual, sound, smell, feelings and mobility. The only one that is not available is taste. This is parallel to the products offered in Kinabalu Park which do not allow visitors to pluck any branches or taste any of its forest products. Multisensory elements enhance visitors experience through the senses which will be memorable in years to come. Learning will take place not immediately but through recalling of memories.
\end{abstract}

\section{Introduction}

Appreciation of tourism products may take in different forms by various types of visitors. Some may appreciate them through any combination of sensual methods namely visualization, feeling, tasting, smelling or hearing. All depends on how visitors are exposed to the said tourism products. Many visitors are concerned only about their final destination without realizing that they are missing the experiences they gathered along the way to their destination. They appreciate most of the time through a small window rather than experiencing the surrounding environment [1-2]. Mass tourism has created this situation [3]. Visual elements dominated tourists' experience [4-5].

Multisensory elements are vital in enhancing visitors' experience in many ways [6]. Any of these elements will help shape local identity of a specific destination [7]. Meaningful experiences can create a closer link between a visitor and his/her environment and thus will lead to a stronger engagement between the two parties (Pine and Gilmore, 1999 cited in [8]). Referred to as the experience economy by Pine and Gilmore, these experiences can be in the form of active or passive experience [8]. Experiences are not only at the heart of tourism marketing but they will also lead to the essence of branding as argued by [8]. 
Experience economy is the fourth economic offering after delivery of services which is merely for goods. Experience economy encourages visitors to be engaged with the environment and create a "unique self-tailored experience that reflects their personality and interest" [8]. In addition, experience obtained through sensory elements will further lead to "long term changes in conservation behaviour" [9] and provides memorable physical reminders [8] to the visitors. Therefore, multisensory elements are needed to enhance visitors' experiences and thus they need to be addressed in tourism [10-11]. Researches on the use of multisensory elements in tourists' experiences are still scarce [6] and are crucial for decision makers [12-13]. Therefore this study intends to assess visitor's experience through multisensory elements in nature based tourism product.

\section{The Role of Multisensory Elements in Tourism}

Due to importance of multisensory elements in tourism research, several related studies have been carried out since 1977. [10] argue that the more a visitor engages with his/her environment the more senses are stimulated. They further elaborate that once a visitor decides to step out of his comfort zone, his/her senses will be freed [14]. In addition, places and visitors' surrounding are associated with sensory elements $[1,15-18]$ and will normally result in many memorable experiences [8, 19-20].

Studies on visual sense are most being carried out. This sensory element deprives a visitor from other senses such as sound, smell, taste and feels or touches [4, 5, 10, 11]. This is due to emergence of mass tourism in which visitors will spend a short holiday break by riding on a tour bus most of the time. Their interaction with the surrounding is limited to the views from a bus window. If the bus is air conditioned, it will be worst as they won't be able to experience the sound and smell of the surrounding [5]. Many scholars disagree with giving visitors only the visual experience. [5, 10, 11], believe that visitors' experiences should be extended to being exposed to other senses other than visual sense. These senses are equally important to visitors' experience $[2,11,21]$ and this includes mobility [22].

Mobility refers to the sensation of movement and considered as the 'sixth' sense [23]. Walking is the only mode of mobility one can use in a forest [22]. It articulates the relationship between a pedestrian and his/her environment [24].

\section{Method and Materials}

\subsection{Study Area}

Qualitative approach is used to achieve this study's objective. Kinabalu Park, a UNESCO World Heritage Site in Sabah was chosen to be the study area. Established in 1964, Kinabalu Park, was declared as a World Natural Heritage Site in 2000. Located in Sabah, Borneo Island, it is the first World Heritage Site in Malaysia [25]. It has an area of $754 \mathrm{~km}^{2}$. Its entry point for visitors is at the Park Headquarters which is located $92 \mathrm{~km}$ from Kota Kinabalu, Sabah, at an elevation of $1520 \mathrm{~m}$ above sea levels [26]. According to [26], more than 250,000 people have visited this park in 2009. Figure 1 shows the map of Kinabalu Park, Sabah, Malaysia. 


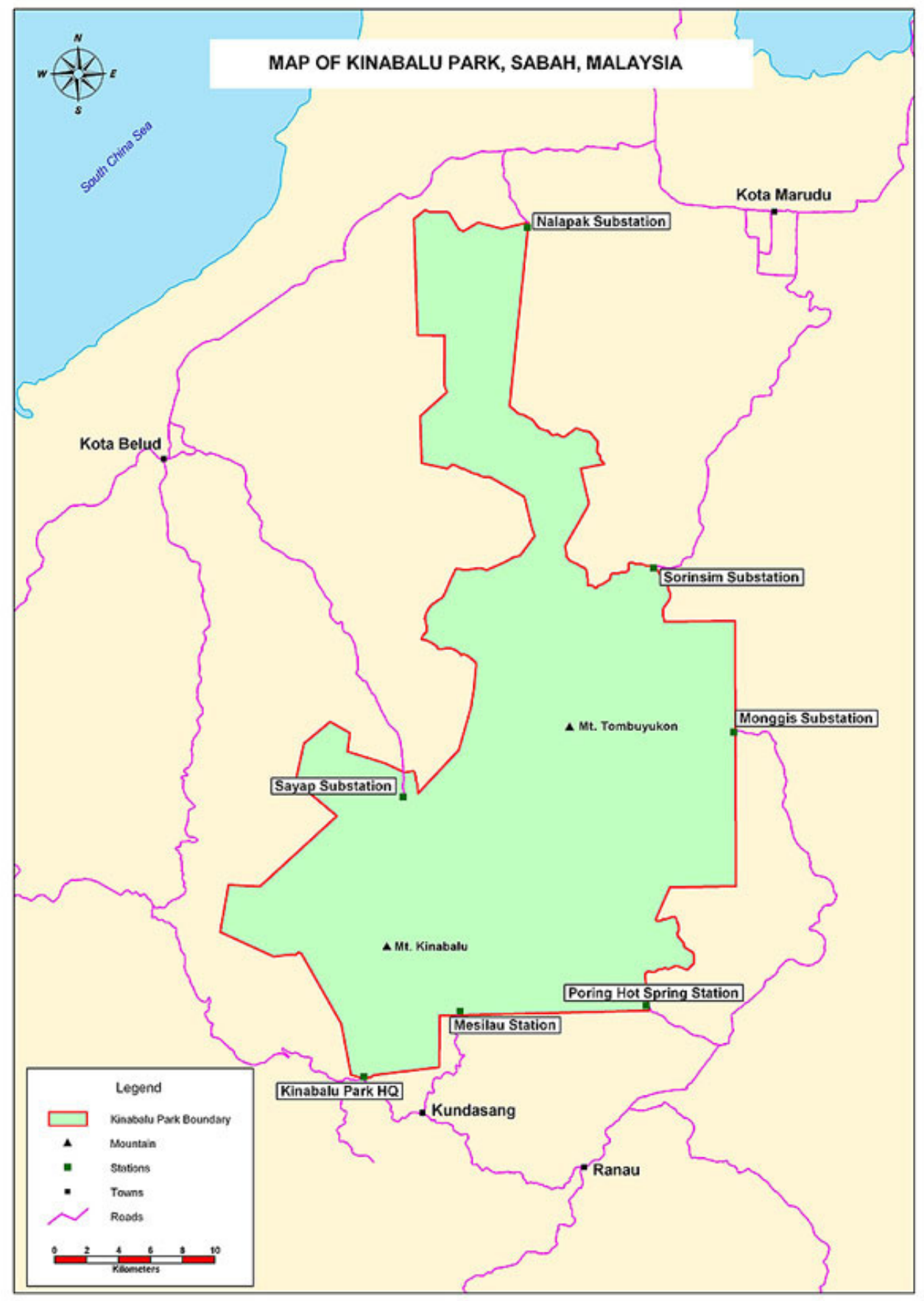

Figure 1. Map of Kinabalu Park, Sabah, Malaysia (25)

\subsection{Methodology}

In this study, participant observation is the method used in data collection. A digital camera is the main tool used to take photographs and video the experience of walking through the forest. However, 
not all sensory elements can be measured using this tool due to its inability to record feeling, smell, taste and mobility. These senses were recorded using human's stimuli responses.

\subsection{Data Collection}

Photographs are used to show the visual sense and video is used to display sound and visual movement. Other senses were measured using human's stimuli reactions or responses. A sensory detail chart is used as an audit list for recording information. It contains sensory elements to be measured and also questions to ask. Table 1 shows the detail of the chart.

Table 1. Sensory Detail Audit Chart

\begin{tabular}{|l|c|c|}
\hline Sensory elements & Questions to be answered & Measurement Tool \\
\hline Sight/Visual & What can be seen? & Digital camera \\
\hline Smell & What is the smell? & Human's stimulus responses through nose \\
\hline Sounds & What can be heard? & Video camera \\
\hline Taste & What can be tasted? & Human's stimulus responses through tongue \\
\hline Feelings/Texture & How do you feel? & $\begin{array}{c}\text { Human's stimulus responses through } \\
\text { excitement }\end{array}$ \\
\hline Mobility & How do you fine walking? & $\begin{array}{r}\text { Human's stimulus responses through } \\
\text { excitement while walking }\end{array}$ \\
\hline
\end{tabular}

\section{Results and Discussion}

Kinabalu Park has three popular substations and points of entry namely, Timpohon (located at Park Headquarters), Mesilau and Poring. These places attract different type of tourists. Timpohon and Mesilau are two places where mountain climbers will assemble before embarking on the trip to the summit of Kinabalu. On the other hand, Poring is a place that attracts visitors with children. Only Timpohon is audited. Timpohon is one of the checkpoints for climbers to participate in the Summit Trail. Figure 2 shows the map of this trail. 


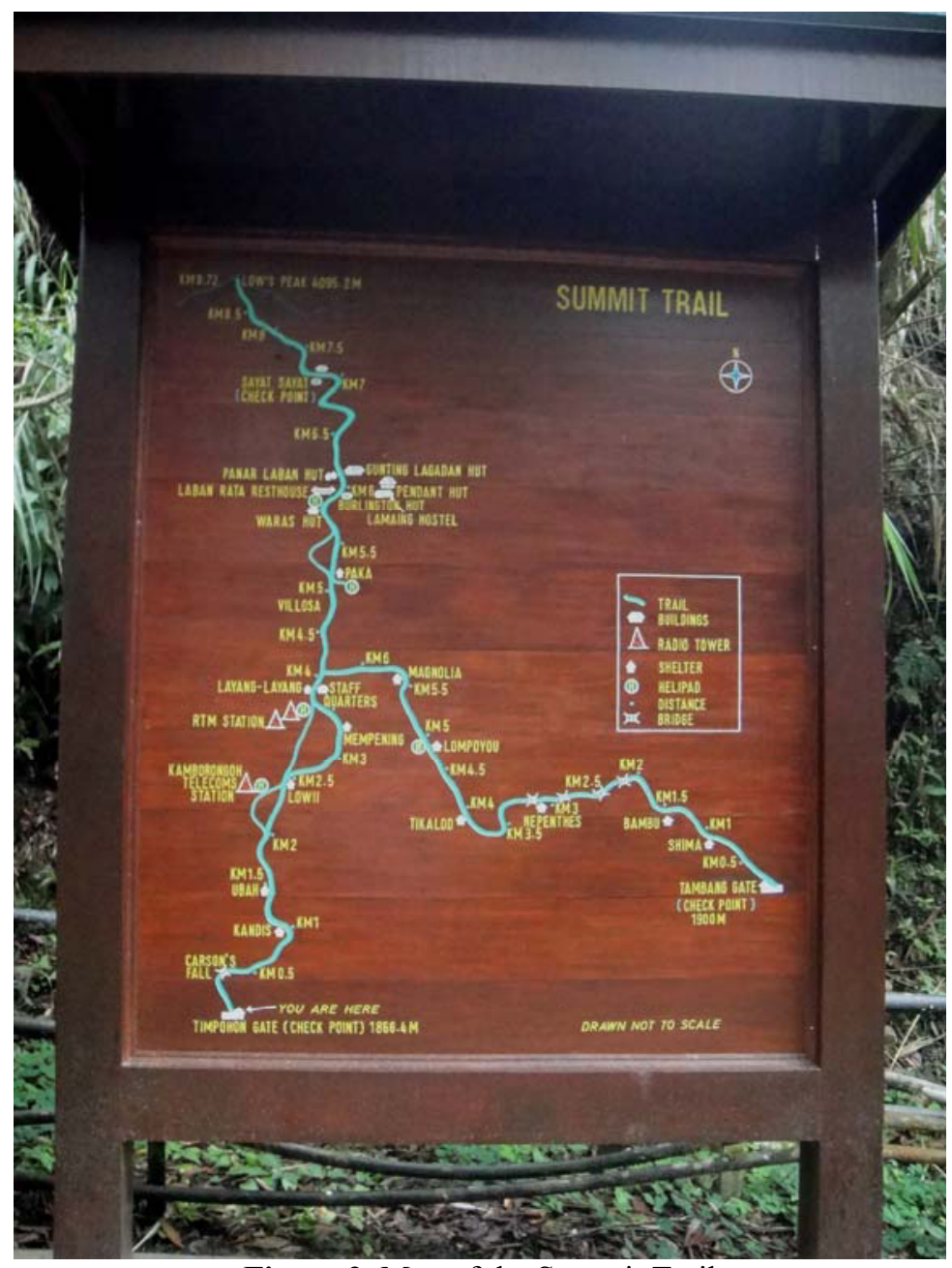

Figure 2. Map of the Summit Trail

Through the selection process using the sensory audit chart, proofs of stimuli for each sense were collected.

\subsection{Visual}

Profile of trees in rainforest can be seen clearly from afar. Wild flowers are available along the trail. Map of the trail is clearly displayed. Mists can be seen coming one's way. Pathway to the summit of Mount Kinabalu is a thrill to walk through. Water fall is another feature that is common at a higher elevation. Climbers and their guide who have completed their journey to the summit are greeted here. Visual sensory is very obvious and prominent. This is similar to previous studies discussed by [4]. However, it differs to what have been said by [5] in which this scenery is not viewed through a metal window but through life experience of the researcher. Figure 3 shows snapshots of the sights in the park. 


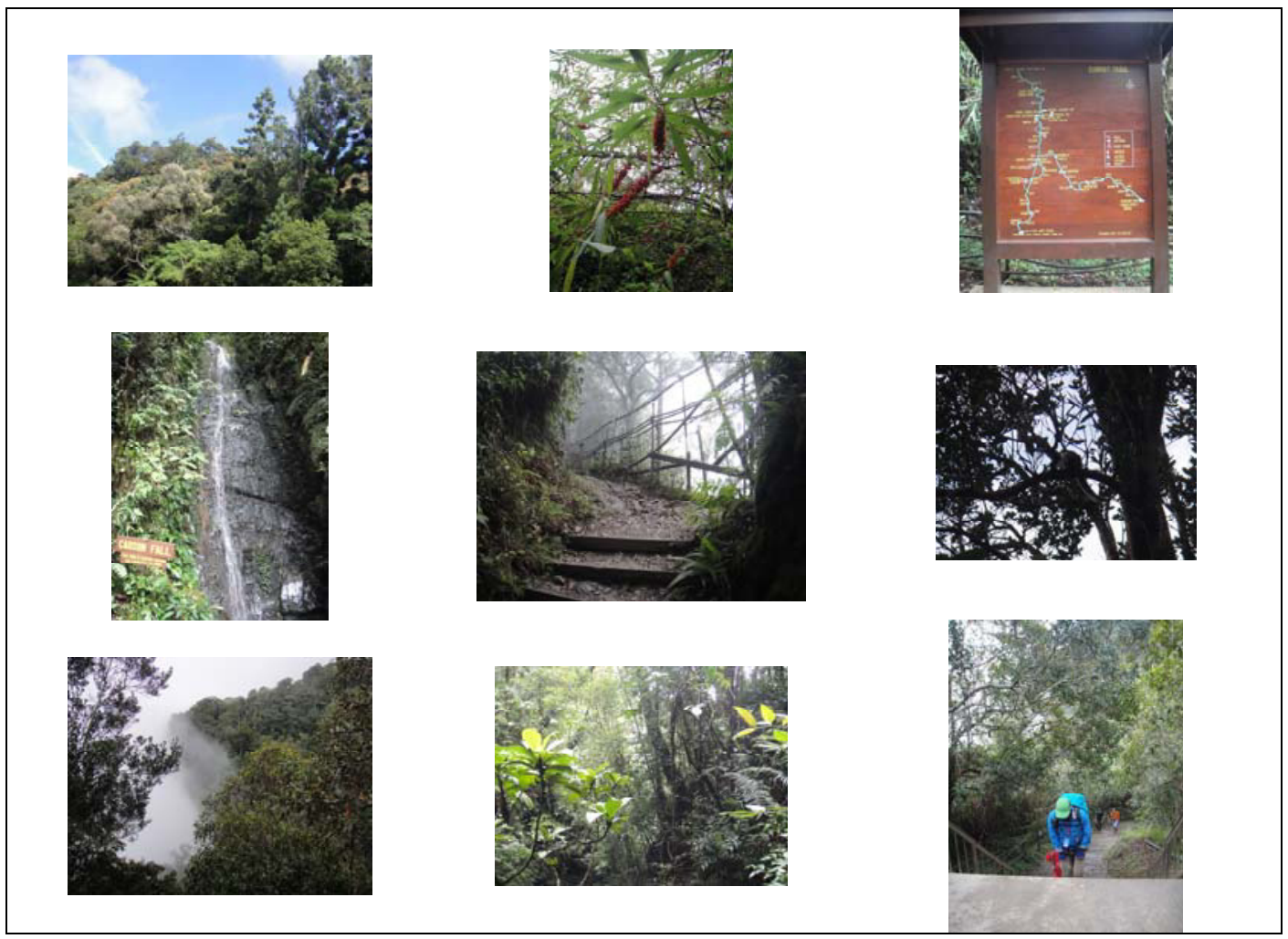

Figure 3. Visuals of Kinabalu Park. Photographs are used

\subsection{Smell}

The smell and sensation of fresh air found in the forest is exhilarating. This is the moment when one decides to stay longer in the forest. Smell tends to be the closest to one's memory [10] and can easily be associated with a place [18].

\subsection{Sound}

One's breathing can be heard after few meters of walking. However, the sound of birds singing and other animals such as squirrel chipping and insect sounds can also be heard. Sound of visitors' panting and whispering among each other is also quite prominent. These are the sounds that be related to the image of the destination [27].

\subsection{Taste}

Taste is not possible in this research. This is due to the park's rules and regulations that prevent visitors from plucking any parts of trees. This is consistent with the statements by [22] which highlights that taste is a sensory element that is addressed mostly in food tourism.

\subsection{Feel}

One can easily feel cool and fresh and energetic. This is due to the green surrounding at a high altitude. However, one can never stop being nervous [22] when climbing an elevation of forty five 
degrees along a narrow walkaway knowing that next to you is a cliff. The heart starts pumping and the excitement can be felt individually and also shared with others.

\subsection{Mobility}

Visitor's movement is limited to a narrow walkway which is often slippery due to high humidity and wet weather. Extra precaution is required when walking along the trail. Visitors might not have a chance to enjoy the surroundings if he/she does not stop to do this. This complements the study done by [22]. Thus senses other than visual and feeling might be used at this moment. Figure 4 shows the difficulty in visitors' mobility.
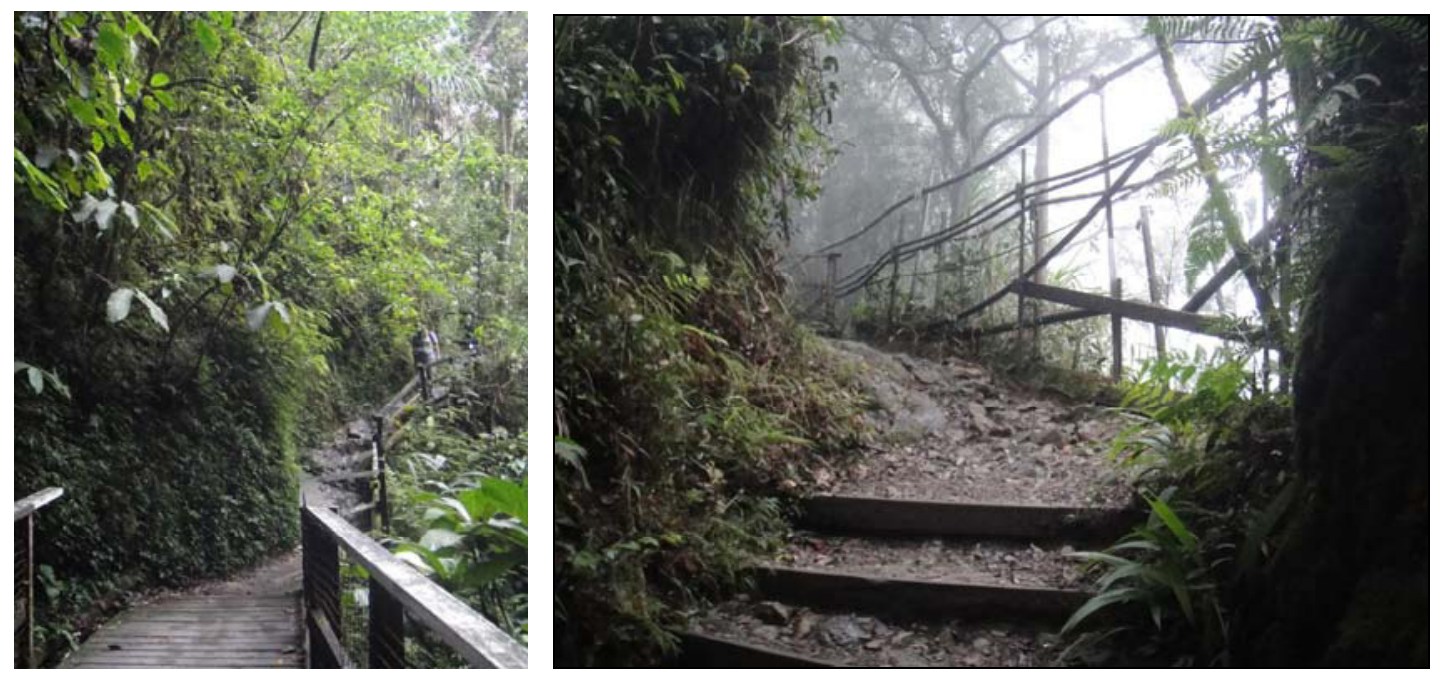

Figure 4. Mobility at Kinabalu Park.

\section{Conclusion}

Audit results present the role of multisensory elements in appreciating Kinabalu Park as a naturebased tourism product. Five sensory elements namely, visual, smell, sound, feeling and mobility, are dominant here. Taste is not a stimulus in this type of tourism since it has nothing to offer in the forest environment. Visitors need to bring their own food and they need to be aware and not to litter the place. Visitors are required to carry their own rubbish out of the area and dispose them at specific places at the check point. They have to make sure anything brought into the forest should be taken out. Only foot print and memories can be taken out of the place. Experience with multisensory elements is a memorable one and will make visitors would want to visit the place again. Beside memories, visitors also are able to learn something about others and other places. Therefore, multisensory elements do play a role in enhancing visitors experience and knowledge.

\section{Acknowledgements}

The author wishes to thank the Ministry of Higher Education (MOHE) and the University of Malaya for a research grant allocation reference no. FP047-2013A under the Fundamental Research Grants Scheme (FRGS). As an associate member of the University Malaya Spatial-Environment Governance for Sustainable Research (UMSERGE), the author would also like to express her utmost appreciation to all parties involved in the study especially the project leader of this research, Dr. Goh Hong Ching. 


\section{References}

1. J. Urry, The tourist gaze. 2ed., London: Sage Publication (2002)

2. G.M.S. Dann and J.K.S. Jacobsen, Tourism smellscapes. Tourism Geographies, 5 ,1, 3-25 (2003)

3. C. Ryan, K. Hughes, and S. Chirgwin, The gaze, spectacle and ecotourism. Annals of Tourism Research, $27,1,148-163$ (2000)

4. C. Rojek, and J. Urry, Touring cultures: transformations of travel and theory, London: Routledge (1997)

5. J. Larsen, Tourism mobilities and the travel glance: experiences of being on the move. Scandinavian J. of Hospitality and Tourism. 1, 2,80-98 (2001)

6. D. Agapito, J. Mendes, and P. Valle, Exploring the conceptualization of the sensory dimension of tourist experiences. J. of Destination Mkt. \& Manage., 2, 2, 62-73 (2013)

7. B. Feintuch, The conditions for Cape Breton fiddle music: the social and economic setting of a regional soundscape. Ethnomusicology, 48 , 1, 73-104 (2004)

8. D. Hayes and N. MacLeod, Packaging places : Designing heritage trails using an experience economy perspective to maximize visitor engagement. J. of Vacation Mkt., 12 , 1, 45-58 (2007)

9. R. Ballantyne, J. Packer, and J. Falk, Visitors' learning for environmental sustainability: Testing short- and long-term impacts of wildlife tourism experiences using structural equation modelling. Tourism Manage.,. 32 , 6, 1243-1252 (2011)

10. S. Pan and C. Ryan, Tourism sense-making: the role of the senses and travel journalism. J. of Travel \& Tourism Mkt., 26, 625-639 (2009)

11. K. Markwell, 'An intimate rendezvous with nature'?: mediating tourist-nature experiences at three tourist sites in Borneo. Tourist Studies, 1, 39-57 (2001)

12. J.H. Gilmore and B.J. Pine Ii, Differentiating hospitality operations via experiences: why selling services is not enough. The Cornell Hotel and Restaurant Administration Quarterly,. 43 , 3,87$96(2002)$

13. B. Schmitt, Experiential Marketing. J. of Mkt. Manage., 15, 1-3, 53-67 (1999)

14. M.S. Carolan, "I do therefore there is": enlivening socio-environmental theory. Environmental Politics, 18 , 1,1-17 (2009)

15. M. Bitner, Servicescapes: The impact of physical surroundings on customers and employees. J. of Mkt., 56, 2, 57-71 (1992)

16. M. Heide and K. GrØnhaug, Atmosphere: Conceptual issues and implications for hospitality management. Scandinavian J. for Hospitality and Tourism, 6, 4, 271-286 (2006)

17. J.D. Porteous, Smellscape. Progress in Physical Geography, 9 , 3, 356-378 (1985)

18. Y-F. Tuan, Space and place: The perspective of experience. Minneapolis: University of Minnesota Press (1977)

19. S. Volo, Conceptualizing Experience: A Tourist Based Approach. J. of Hospitality Mkt. \& Manage., 18, 2-3, 111-126 (2009)

20. J. Pine II, and J. Gilmore, Welcome to the experience economy. Harvard Business Review, 76 ,4,97-105 (1998)

21. A. Son and P. Pearce, Multi-faceted image assessment: International students' views of Australia as a tourist destination. J. of Travel and Tourism Mkt.. 18 , 4,21-35 (20050

22. B.v. Hoven, Multi-sensory tourism in the Great Bear Rainforest. Landabréfið, 25 (2011)

23. N. Lewis, The climbing body, nature and the experience of modernity. Body \& Society,. 6 , 3-4, 58-80 (2000)

24. T. Edensor, Walking in the British Countryside: Reflexivity, Embodied Practices and Ways to Escape. Body \& Society, 6 , 3-4, 81-106 (2000) 
25. UNESCO World Heritage Center. Decision 24COM XA 1 Kinabalu Park (Malaysia). Available from: http://whc.unesco.org/en/decisions/2430. (2012)

26. The Sabah Parks Board Of Trustees. Welcome Kinabalu Park, Malaysia's 1st World Heritage Site. [cited 201428 August]; Available from: http://www.sabahparks.org.my/theparks/kinabalu-park (2014)

27. C.R. Gibson and J. Connell, Music, tourism and the transformation of Memphis. Tourism Geographies, 9, 2, 160-190 (2007) 